\title{
scripted
}

Volume 15, Issue 2, October 2018

\section{Guest Editorial: Contemporary Issues at the intersection of Intellectual Property Law and Society}

\author{
Smita Kheria* \\ (c) (i) $(9)$ \\ (C) 2018 Smita Kheria \\ Licensed under a Creative Commons Attribution-NonCommercial- \\ NoDerivatives 4.0 International (CC BY-NC-ND 4.0) license
}

DOI: $10.2966 /$ scrip. 150218.170

\footnotetext{
* Senior Lecturer in Intellectual Property Law, School of Law, University of Edinburgh, United Kingdom, smita.kheria@ed.ac.uk
} 
This special issue of SCRIPTed contains a collection of five articles: four from the "Intellectual Property" stream of the Socio-Legal Studies Association's annual conference in 2017, held in Newcastle; and, one from the regular submissions received by the journal. The Socio-Legal Studies Association's annual conference, running since 1990, facilitates the discussion and dissemination of recent research in the field of socio-legal studies. ${ }^{1}$ The Intellectual Property stream ${ }^{2}$ attracts papers that explore challenges and opportunities in calibrating aspects of the intellectual property framework, whether domestic, regional, or international, to changes in the economy, technology, and society; and such research is often underpinned by a range of research approaches, including empirical, historical, contextual, and theoretical. The articles in this special issue reflect this diversity in topics and approaches and covers a range of contemporary issues: the future of UK's participation in the unitary patent package in light of Brexit, the relationship between trade marks and consumerism, the effect of digitalisation on the value chain and market structure in the music industry, the relationship between copyright enforcement through algorithms and cultural diversity, and the tension between the principle of territoriality and increasing assetization of intellectual property.

In the first article, Aisling McMahon tackles the future of the UK's participation in the unitary patent package in light of Brexit. By reviewing recent political and legal developments, and their potential consequences, she examines the extent to which the UK can be a part of both the European Patent with Unitary effect, and the Unified Patent Court system. In particular, she highlights the

1 Socio-Legal Studies Association, "Annual Conference", available at https://www.slsa.ac.uk/index.php/annual-conference (accessed 23 October 2018).

2 Socio-Legal Studies Association, "Intellectual Property", available at https://slsa2019.com/streams-current-topics/intellectual-property/ (accessed 23 October 2018). 
challenges that might arise due to the relationship between the EU and the Unified Patent Court system, as well as the legal measures and the political compromise that might be required to accommodate the UK's participation in it post-Brexit. McMahon concludes by looking ahead to the potential economic consequences of the resulting complex and fragmented framework of patent protection, and calls for a rethink towards a more inclusive unitary patent system.

Andrew Griffiths focuses on the relationship between trade marks and consumerism. He reviews the nature of consumerism, to flesh out the role played by trade marks in facilitating and supporting the growth of consumerism, particularly in how trade marks have enabled firms to economically exploit facets of the consumer society. He uses this analysis to ultimately flag up important issues in terms of the social cost of consumerism, such as the impact of consumerism on the environment and the labour conditions in the production process; and, to bring to the fore the justifications for trade mark protection and the need for further measures to mitigate the social cost of consumerism.

The premise for the next two papers is copyright and digital technologies. Morten Hviid, Sofia Izquierdo-Sanchez, and Sabine Jacques discuss the effect of digitalisation on the value chain and market structure in the music industry, by charting recent developments in the consumption of music from the advent of CDs up to the recent uptake in subscription-based streaming. While exploring the role of the copyright framework in these developments, and the potential impact on creators, they argue that both the production of music at record level, and its distribution at retail level, are now concentrated oligopolies. They conclude that intermediaries continue to play a role in the chain of digital musical distribution but there has been a shift in their roles and power.

Sabine Jacques, Krzysztof Garstka, Morten Hviid, and John Street discuss the impact of copyright enforcement through algorithms on cultural diversity. 
They examine the impact of Content ID, YouTube's digital finger-printing and algorithm-based, automated anti-piracy system, on the diversity of expressions in a sample of musical parodies on the platform, during the period of 2012-2016. While sharing their findings on the limited co-relation between enforcement through Content ID and cultural diversity in the musical parodies, both supplied and consumed, on the platform, they pose further questions for future research on cultural diversity in user-generated content. They conclude with a range of suggestions in relation to automated anti-piracy systems and copyright exceptions, which could help preserve and promote cultural diversity in an online environment.

Finally, Emmanuel Kolawole Oke examines the tension between the principle of territoriality in international intellectual property law and the increasing assetization of intellectual property in international investment agreements. He contextualises the continued role for, and importance of, the principle of territoriality, and explains how a country's freedom to calibrate national intellectual property laws is challenged when IP rights become investment assets. His analysis focuses on two investment arbitration disputes from Uruguay and Canada, which he uses as illustrative examples to argue that there remains scope for preserving the principle of territoriality, and consequently ensuring that choices made by countries as policy goals and in the public interest, are respected. Oke calls for the adoption of a broader interpretative approach by investment tribunals.

With the ever-increasing role and impact of Intellectual Property law, scholars are asking some fundamental questions about the nature and importance of IP rights in the context of rapid development of new technologies, specific changes in the behaviour of producers, users, and intermediaries, and wider developments in the economy and society. This special issue contributes to the discourse by drawing attention to some contemporary issues at the 
intersection of Intellectual Property Law and Society: What is the role of IP in facilitating, and mitigating the impact of consumerism? Do countries still have the freedom to devise IP policies that are aimed at national objectives and goals? Can the IP framework reward and facilitate the expression of different types of creators, while also accommodating public interest in cultural diversity and access to creative expressions? The articles in this issue, while responding to diverse contemporary challenges, are thematically connected in their underlying focus and scrutiny on the mutual relationship between intellectual property law, politics, culture, and the economy.

Thank you to the authors, peer reviewers, student editors and the editorial team, for their help and sustained efforts in organising this special issue. I hope that the readers of SCRIPTed enjoy it. 